\title{
Recent advances in the management of type 2 diabetes mellitus: a review
}

\author{
B T Srinivasan, ${ }^{1,2}$ J Jarvis, ${ }^{1}$ K Khunti, ${ }^{3}$ M J Davies ${ }^{2}$
}

${ }^{1}$ Department of Diabetes Research, University Hospitals of Leicester NHS Trust, Leicester, UK: ${ }^{2}$ Department of

Cardiovascular Sciences, University of Leicester Leicester, UK; ${ }^{3}$ Department of Health Sciences, University of Leicester, Leicester, UK

Correspondence to: J Jarvis, Diabetes Research, Level 1, Victoria Building, Leicester Royal Infirmary, Infirmary Square, Leicester, LE1 5WW, UK; janet.jarvis@ uhl-tr.nhs.uk

Received 8 May 2008 Accepted 12 August 2008

\section{ABSTRACT}

Type 2 diabetes mellitus (T2DM) is a progressive disorder caused by a combination of insulin resistance and $\beta$ cell dysfunction. It is associated with an increased and premature risk of cardiovascular disease as well as specific microvascular complications such as retinopathy, nephropathy and neuropathy. In the last 5 years new glucose lowering drugs acting on novel pathways have been developed, licensed and launched, such as the glucagon-like peptide (GLP-1) agonists (exenatide) and dipeptidyl peptidase (DPP-IV) inhibitors such as sitagliptin and vildagliptin. This review looks at these new agents in terms of their mode of action, pharmacokinetics and use in clinical practice. This review also includes new agents in the area of weight loss that may have a positive effect for glucose management-for example, rimonabant.

Type 2 diabetes mellitus (T2DM) is a complex multifactorial disease affecting the length and quality of life of an affected individual. In the UK prevalence of diabetes is $3.66 \%$ or 2.3 million people diagnosed, ${ }^{1}$ consuming around $10 \%$ of total National Health Services resources annually. ${ }^{2}$ Established macrovascular pathology is common at the time of diagnosis of T2DM, suggesting either latency in diagnosis and/or an atherogenic pre-diabetes state $^{34}$ It is estimated that, in 2006, some 194 million people worldwide, or $5.1 \%$ of the adult population, had diabetes. ${ }^{5}$

T2DM is a progressive disorder accompanied by deterioration in $\beta$ cell function ${ }^{6}$ and insulin resistance. Despite this, there is now clear evidence that tight control of blood glucose significantly reduces the risk of complications of diabetes. Before the year 2000 the choice of pharmacological agents, especially oral agents, to treat T2DM was limited. Sulfonylureas and metformin are cost effective and are still regularly used in clinical practice; however, both have their disadvantages.

Sulfonylureas have been in use since the 1950s and were developed following an observation by two scientists that sulfonamides had a glucose lowering effect. There are many sulfonylureas available and they act by stimulating insulin secretion from the pancreas. Due to their mode of action they do rely on some residual $\beta$ cell function and will therefore become less effective as diabetes progresses. Sulfonylureas are associated with hypoglycaemia and weight gain. Side effects with this class of drugs are rare.

The biguanides were launched in the 1950s and metformin is currently the only one available; phenformin and buformin were withdrawn in the 1970s following safety concerns due to a risk of fatal lactic acidosis. Despite the cardioprotective effect of metformin, many patients fail to tolerate maximum doses due to gastrointestinal side effects. Metformin is the only biguanide available and acts by decreasing gluconeogenesis and increasing peripheral utilisation of glucose. It is often used in overweight patients due to its weight neutrality.

Acarbose is an $\alpha$ glucosidase inhibitor and has been available since the 1990s. It inhibits the enzymes needed to digest carbohydrates and is therefore taken with meals. This drug is rarely used in the UK due to common side effects such as flatulence and diarrhoea but is used regularly in other countries such as Japan. Around the same time meglitinides were launched. These agents (repaglinide and nateglinide) stimulate insulin release and are taken with main meals. Side effects can include weight gain and hypoglycaemia.

Thiazolidinediones (TZDs) were also introduced in the late 1990s and these agents act by binding to PPAR $\gamma$ thus reducing insulin resistance. One of the main side effects is water retention, leading to oedema and weight gain. TZDs are more costly than the traditional agents such as metformin and sulfonylureas.

Due to the progressive nature of T2DM, many individuals require insulin to optimise glycaemic control over time as oral hypoglycaemic agents fail to achieve targets. Data from the UK Prospective Diabetes Study suggest that $53 \%$ of patients will require insulin after 6 years following diagnosis and $75 \%$ of patients will need multiple treatments after 9 years. $^{89}$

Although insulin treatment is very effective in achieving glycaemic control, its use is invariably associated with weight gain due to increased body fat mass, in particular abdominal obesity. ${ }^{10} 11$ Increased abdominal obesity in turn may lead to worsening of insulin resistance and therefore increasing insulin requirements, and a vicious circle may ensue. Along with weight gain, insulin use can also cause problems with episodes of hypoglycaemia if insulin treatment is not managed appropriately.

There is clearly a need for newer pharmacological agents acting through novel mechanisms which could be used instead of or in combination with insulin, especially in light of the recent concerns regarding the cardiovascular safety of rosiglitazone, a TZD. ${ }^{12}$ On the other hand, a statistically nonsignificant reduction in primary composite end point (defined as death from any cause, non-fatal myocardial infarction (including silent myocardial infarction), stroke, acute coronary syndrome, leg amputation, coronary or leg revascularisation) was shown with pioglitazone $(n=2605)$ compared 
with placebo $(\mathrm{n}=2603)$ in patients with T2DM (514 vs 572 , hazard ratio (HR) $0.90,95 \%$ confidence interval (CI) 0.80 to $1.02 ; \mathrm{p}=0.095){ }^{13}$

This review will discuss the next generation of agents available to treat T2DM. Newer agents that act differently to the previous generation of agents that address weight gain and preservation of $\beta$ cell mass are of particular interest. We have seen a rapid influx of these new agents over the past 2 years and it is important for general physicians to have an evidence base and working knowledge on the practical use of these medications.

The aim of this review is to provide an overview of the newer modalities of treatment that have become available over the last 2 years and discuss how they have addressed some of the shortfalls of current treatment options for T2DM. For the purpose of this review OVID Medline was searched in the month of January 2008. Previous systematic reviews, metaanalysis, and double blinded randomised controlled trials in English and in human subjects were reviewed.

\section{OVERVIEW}

\section{Incretin mimetics}

Insulin has been shown to be released more effectively through an oral glucose load than intravenously and this is known as the incretin effect. ${ }^{14}$ The incretin effect occurs when intestinally derived peptides (one of these peptides is glucagon-like polypeptide 1 (GLP-1)) stimulate insulin release in response to oral glucose. However, the insulin stimulating benefits of peptides such as GLP-1 are rapidly diminished as GLP-1 is rapidly metabolised by the glycoprotein dipeptidyl peptidase (DPP-IV). Considering the incretin effect it is possible to enhance the incretin pathway in two ways: by enhancing the action of GLP-1 itself, or by slowing its breakdown by inhibiting the release of DPP-IV.

\section{Glucagon-like polypeptide 1 analogues}

Exenatide is the first agent belonging to the class of GLP-1 agonists. It is a synthetic version of exendin- 4 which is a hormone found in the saliva of the Gila monster (a lizard native to the USA) which has properties similar to human GLP-1. GLP1 belongs to the class of small intestinal hormones that has an insulinotropic action in response to ingested glucose. In addition, GLP-1 suppresses inappropriately high glucagon values which in turn suppress hepatic glucose output. It also reduces the rate of gastric emptying, thus promoting satiety, resulting in reduced caloric intake and weight reduction. ${ }^{15}$ There is also evidence to suggest that GLP-1 analogues may preserve $\beta$ cell reserves. This evidence is from animal studies and more recently from analysis of $\beta$ cell function using validated surrogate markers such as HOMA- $\beta .^{16-18}$ As the GLP-1 analogues cause glucose dependent insulin release in the postprandial state, they have a lower risk of hypoglycaemic episodes compared to insulin. In addition they also potentiate weight reduction by mediating satiety and reduced gastric emptying. ${ }^{19}$ Exenatide is the first licensed injectable hypoglycaemic agent that has clearly shown a statistically significant weight reduction compared to insulin/placebo.

The recently published data ${ }^{18}$ on subjects completing over 2 years of treatment with exenatide showed a sustained reduction in $\mathrm{HbA1c}$ and weight after 104 weeks of treatment ( $\mathrm{n}=283$, mean (SEM) reductions from baseline: HbAlc -1.1 (0.1)\%, 95\% CI $-1.3 \%$ to $-1.0 \%, p<0.001$; weight $-4.7(0.3)$ $\mathrm{kg}, 95 \% \mathrm{CI}-5.4 \mathrm{~kg}$ to $-4.0 \mathrm{~kg}, \mathrm{p}<0.001) .{ }^{18}$ Further, this study has also reported reduction in markers of hepatic injury (surrogate markers of cardiovascular risk) and improvement in $\beta$ cell function as measured by HOMA- $\beta$.

For the purposes of this review we have pooled the data on exenatide into two categories: firstly, exenatide in combination with oral antidiabetic agents; and secondly, exenatide compared with insulin.

\section{Exenatide and oral antidiabetic agents}

Three studies ${ }^{20-22}$ have compared exenatide with placebo in combination with a sulfonylurea or metformin in randomised double/triple blinded trials. The duration of these studies varied between 16-30 weeks and involved over 1000 participants (table 1). In all of these studies treatment with exenatide produced significant reductions in $\mathrm{HbA1c}$ and more weight loss compared to placebo. In these studies exenatide was generally well tolerated by participants. When used in combination with TZD treatment ${ }^{23}$ exenatide resulted in significant reductions in HbA1c ( $-0.89 \%$ vs $-0.09 \%)$ and weight $(-1.75 \mathrm{~kg}$ vs $-0.24 \mathrm{~kg})$ compared to placebo; however, there were more gastrointestinal symptoms in the exenatide groups.

\section{Exenatide compared to insulin}

Two studies (one using biphasic insulin and one using basal insulin) ${ }^{24} 25$ comparing insulin treatment with twice daily exenatide showed exenatide to be comparable to insulin in terms of $\mathrm{HbA1c}$ reduction. Although similar improvement in overall glycaemic control was seen with exenatide, more gastrointestinal adverse events were reported in this group. In these studies weight loss was seen with exenatide treatment compared to weight gain in the insulin groups. In a 16 week crossover study ${ }^{26}$ comparing exenatide to insulin glargine, a similar reduction in $\mathrm{HbA1c}$ was once again seen for both treatments; however, a lower rate of overall and nocturnal hypoglycaemia was seen with the exenatide group. Again exenatide was associated with significant weight loss whereas insulin was associated with weight gain.

The meta-analysis by Amori et al ${ }^{16}$ evaluated the safety of exenatide and has reported nausea and vomiting to be the most common side effects with the agent. Hypoglycaemic event rate was similar to that of insulin, but higher compared to placebo. These tend to occur at the initiation stage and were common when exenatide was co-administered with a sulfonylurea. Severe hypoglycaemia was rare. ${ }^{16}$ Recently, reports of pancreatitis in patients taking exenatide have been seen by postmarketing surveillance, ${ }^{27}$ although a causal relationship remains to be uncovered. As GLP-1 analogues slow gastric motility, it is plausible they also cause reduced biliary duct motility and promote biliary sludge and thus biliary obstruction, but this remains unexplained.

In summary, GLP-1 analogues are a potentially beneficial option for the treatment of T2DM and are novel in enhancing weight reduction. In addition, animal studies have shown preservation of $\beta$ cell function. Further evidence on cardiovascular disease risk remains to be seen. Long acting analogues of exenatide are in clinical trial phase as is liraglutide, the second GLP-1 analogue, which appears to be associated with lower rates of vomiting compared to exenatide. In this trial there were no withdrawals due to gastrointestinal side effects. ${ }^{28}$

In clinical practice, exenatide is considered for use in obese people with T2DM on oral hypoglycaemic agents who do not achieve HbA1c targets. Exenatide is subcutaneously injected and can be used with either metformin or a sulfonylurea alone 
Table 1 Characteristics of studies comparing exenatide and other oral hypoglycaemic agents

\begin{tabular}{|c|c|c|c|c|c|c|c|c|}
\hline Source & $\begin{array}{l}\text { Trial length } \\
\text { (weeks) }\end{array}$ & $\begin{array}{l}\text { Number of } \\
\text { subjects }\end{array}$ & Treatment and dose & $\begin{array}{l}\text { Duration } \\
\text { diabetes } \\
\text { (years) }\end{array}$ & $\begin{array}{l}\text { Mean } \\
\text { baseline } \\
\text { HbA1c }\end{array}$ & $\begin{array}{l}\text { Change in } \\
\text { HbA1c }\end{array}$ & Hypos & $\begin{array}{l}\text { Change in } \\
\text { weight } \\
\text { (kg) }\end{array}$ \\
\hline \multicolumn{9}{|c|}{ Exenatide versus placebo in combination with $O A D s$} \\
\hline \multirow{2}{*}{ Buse $2004^{20}$} & & & Ex $10 \mu \mathrm{g}$ once daily $+\mathrm{SU}$ & 6.6 & 8.6 & $-0.86^{* *}$ & $36 \%$ & $-1.6^{*}$ \\
\hline & & & Placebo + SU & 5.7 & 8.7 & +0.12 & $3 \%$ & -0.6 \\
\hline DeFronzo $2005^{21}$ & 30 & 336 & Ex $5 \mu \mathrm{g}$ once daily $+\mathrm{MF}$ & 6.2 & 8.3 & $-0.4^{* *}$ & $4.5 \%$ & $-1.6^{*}$ \\
\hline \multirow[t]{3}{*}{ Kendall $2005^{22}$} & 30 & 733 & $\mathrm{Ex} 5 \mu \mathrm{g} \pm \mathrm{OAD}$ & 8.7 & 8.5 & $-0.55^{* *}$ & $19.2 \%$ & $-1.6^{* *}$ \\
\hline & & & Ex $10 \mu \mathrm{g} \pm 0 A D$ & 8.7 & 8.5 & $-0.77^{* *}$ & $27.8 \%$ & $-1.6^{* *}$ \\
\hline & & & Placebo $\pm 0 A D$ & 9.4 & 8.5 & +0.23 & $12.6 \%$ & -0.9 \\
\hline \multirow[t]{2}{*}{ Zinman $2007^{23}$} & 16 & 233 & Ex $5 / 10 \mu \mathrm{g}+\mathrm{TZD}$ & 7.3 & 7.9 & $-0.89^{*}$ & $10.7 \%$ & $-1.75^{*}$ \\
\hline & & & Placebo + TZD & 8.2 & 7.9 & +0.09 & $7.1 \%$ & -0.24 \\
\hline \multicolumn{9}{|c|}{ Exenatide versus insulin } \\
\hline Barnett 2007 & 16 x over & 138 & Ex $10 \mu \mathrm{g}$ twice daily $+1 \mathrm{OAD}$ & & & -0.36 & Lower overall hypo & -1.6 \\
\hline & & & Insulin + $10 A D$ & & & -1.36 & $\begin{array}{l}(p=0.039) \text { and nocturnal } \\
\text { hypo }(p<0.001) \text { with } \\
\text { exenatide }\end{array}$ & +0.6 \\
\hline
\end{tabular}

${ }^{*} p \leqslant 0.05 ;{ }^{* *} p \leqslant 0.01$

Ex, exenatide; MF, metformin; $O A D$, oral antidiabetic agent (could be metformin or sulfonylurea); SU, sulfonylurea.

or in combination with both. Exenatide is commenced at a dose of $5 \mu \mathrm{g}$ twice daily and is increased to $10 \mu \mathrm{g}$ after 12 weeks subject to patient tolerance. Potentially in obese patients who are receiving $>100$ units of insulin, exenatide may be useful as an alternative to prandial insulin. However, the combination of basal insulin and exenatide has not been the subject of clinical trials and is thus unlicensed, and therefore should be used with extreme caution under specialist supervision only.

The Scottish Medicines Consortium ${ }^{29}$ published guidance on the use of exenatide in June 2007 which stated that exenatide was accepted for restricted use in Scotland for the treatment of T2DM. They stated it should be used in combination with metformin and/or sulfonylureas in those patients who have failed to achieve glycaemic control on maximally tolerated doses of these agents. It is restricted for use as an alternative to insulin in patients who have failed treatment on metformin and/or sulfonylureas and in whom insulin would be the next treatment option.

The National Institute for Health and Clinical Excellence (NICE) has recently updated their guidelines for the management of T2DM which includes guidance on the use of exenatide. ${ }^{30}$ They state that exenatide is not recommended for routine use in T2DM and it should only be considered as an option if an individual fulfils one of the following criteria:

- Has a body mass index (BMI) $>35 \mathrm{~kg} / \mathrm{m}^{2}$

- Has specific problems of a psychological, biochemical or physical nature arising from high body weight

- Has inadequate glucose control (HbA1c $\geqslant 7.5 \%)$ with conventional oral agents

- If another high cost medication such as a TZD or insulin would otherwise be started.

They go on to state that treatment with exenatide should only be continued if a $1.0 \%$ reduction in $\mathrm{HbA} 1 \mathrm{c}$ has been seen at 6 months and at least a $5 \%$ weight loss is seen at 1 year.

\section{Dipeptidyl peptidase inhibitors}

DPP-IV inhibitors such as sitagliptin and vildagliptin are novel new treatments for T2DM as they work by targeting both prandial and fasting glucose concentrations. This class of agent works by enhancing the sensitivity of $\beta$ cells to glucose, which causes enhanced glucose dependent insulin secretion. It has also been shown to improve markers of $\beta$ cell function. Many studies using sitagliptin and vildagliptin alone or in combination have shown a positive effect on values of $\mathrm{HbA1c} .^{31}$

\section{Gliptins used as monotherapy}

Various trials have reported results with vildagliptin or sitagliptin as monotherapy compared to placebo (table 2). ${ }^{32-34}$ Trial length varied between 18-24 weeks and all trials showed a significant reduction in $\mathrm{HbA} 1 \mathrm{c}$ of between $0.48-0.94 \%$, with either weight loss or weight neutrality. Vildagliptin and sitagliptin, when compared head to head with metformin in two trials, ${ }^{35} 36$ showed a reduction in $\mathrm{HbA1c}$, although with metformin the reductions were greater. In these studies the gliptins either caused small weight gain or were weight neutral compared to metformin, which showed reductions in weight.

\section{Gliptins used in combination with metformin}

There have been many studies ${ }^{36-40}$ examining the effects of gliptins when used as dual therapy with metformin. These studies compared a gliptin with metformin versus a placebo with metformin. Reduction in HbA1c in the gliptin arms ranged between $0.6-2.07 \%$ with weight loss or weight neutrality.

\section{Gliptins used in combination with sulfonylureas}

Trials examining the effect of gliptins in combination with sulfonylureas ${ }^{41}{ }^{42}$ have also showed beneficial effects on HbA1c with reductions ranging from $0.57-0.89 \%$ accompanied by weight loss. A study by Nauck et $a^{143}$ compared a combination of sitagliptin and metformin versus sulfonylurea and metformin. 
Table 2 Dipeptidyl peptidase (DPP-IV) inhibitor clinical trials

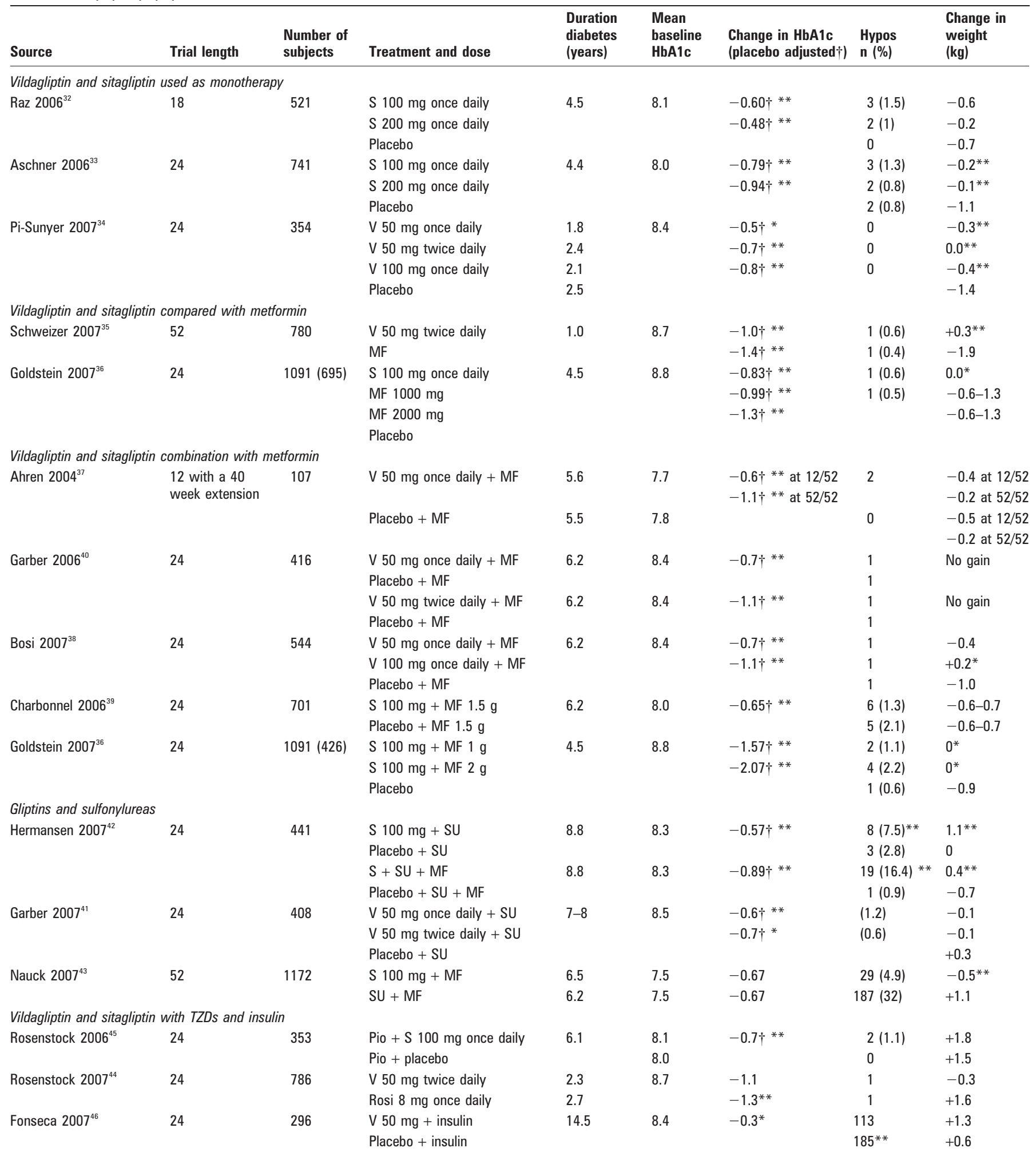

${ }^{*} p \leqslant 0.05 ;{ }^{* *} p \leqslant 0.01$.

MF, metformin; OAD, oral antidiabetic agent (could be metformin or sulfonylurea); Pio, pioglitazone; Rosi, rosiglitazone; S, sitagliptin; SU, sulfonylurea; TZDs, thiazolidinediones; V, vildagliptin.

Although both of these combinations reduced HbA1c, there was no statistical difference between groups.

Gliptins, TZDs and insulin

In a study where rosiglitazone was used head to head with vildagliptin both agents similarly reduced HbA1c; however, vildagliptin caused a small weight loss whereas a $1.6 \mathrm{~kg}$ gain was seen in the rosiglitazone group. ${ }^{44}$ In patients taking pioglitazone, sitagliptin was added and compared with a placebo in a 24 week double blind trial. Significant reductions in $\mathrm{HbA1c}$ were seen in the sitagliptin group ${ }^{45}$; however, weight gain of $>1 \mathrm{~kg}$ was seen in both groups. In combination with 
Table 3 Summary of newer agents for the treatment of type 2 diabetes mellitus

\begin{tabular}{|c|c|c|c|c|c|c|}
\hline Drug & Class & Dose & Benefits & $\begin{array}{l}\text { HbA1c } \\
\text { reduction }\end{array}$ & Problems/cautions & Clinical use \\
\hline Exenatide & GLP-1 agonist & $\begin{array}{l}5 \mu \mathrm{g} \text { twice daily } \\
\text { increasing to } 10 \mu \mathrm{g} \\
\text { twice daily after } \\
12 \text { weeks }\end{array}$ & $\begin{array}{l}\text { Weight reduction } \\
\beta \text { cell preservation in } \\
\text { animal studies } \\
\text { Suppresses appetite }\end{array}$ & $\begin{array}{l}-0.4 \% \text { to } \\
-1.11 \%\end{array}$ & $\begin{array}{l}\text { Gastrointestinal side } \\
\text { effects } \\
\text { Subcutaneous injections }\end{array}$ & $\begin{array}{l}\text { Used with metformin or sulfonylurea } \\
\text { alone or in combination with both }\end{array}$ \\
\hline Sitagliptin & DPP-IV inhibitor & $100 \mathrm{mg}$ once daily & $\begin{array}{l}\text { Targets prandial and } \\
\text { fasting glucose levels } \\
\text { Improves markers of } \beta \text { cell } \\
\text { function }\end{array}$ & $\begin{array}{l}-0.3 \% \text { to } \\
-1.1 \%\end{array}$ & $\begin{array}{l}\text { Renal impairment } \\
\text { Can potentiate digoxin }\end{array}$ & $\begin{array}{l}\text { Can be used with metformin, } \\
\text { sulfonylurea or TZD. Can be used in } \\
\text { triple combination with metformin and } \\
\text { sulfonylurea }\end{array}$ \\
\hline Rimonabant & $\begin{array}{l}\text { Endocannabinoid } \\
\text { receptor blocker }\end{array}$ & $\begin{array}{l}20 \mathrm{mg} \text { once daily } \\
\text { before breakfast }\end{array}$ & $\begin{array}{l}\text { Weight loss } \\
\text { Improved insulin } \\
\text { sensitivity } \\
\text { Suppresses appetite }\end{array}$ & $\begin{array}{l}-0.1 \% \text { to } \\
-0.6 \%\end{array}$ & $\begin{array}{l}\text { Associated with } \\
\text { depressive mood } \\
\text { disorders. Concomitant } \\
\text { antidepressants are a } \\
\text { contraindication } \\
\text { Side effects: upper } \\
\text { respiratory tract infections, } \\
\text { nausea, vomiting, } \\
\text { diarrhoea }\end{array}$ & $\begin{array}{l}\text { Used at any stage of treatment with } \\
\text { other oral hypoglycaemic agents }\end{array}$ \\
\hline
\end{tabular}

DPP-IV, dipeptidyl peptidase; FDA, US Food and Drug Administration; GLP-1, glucagon-like peptide; TZD, thiazolidinedione.

insulin treatment, ${ }^{46}$ reductions in $\mathrm{HbA} 1 \mathrm{c}$ are also seen, although more weight gain is also seen compared to insulin and placebo.

The effect of weight associated with the use of DPP-IV inhibitors has been reviewed in a meta-analysis using data from 13 trials. ${ }^{16}$ This paper found a small weight increase compared with placebo; however, some studies have reported weight loss with sitagliptin compared to sulfonylureas. ${ }^{43}$ Overall this class of drugs appears to be weight neutral ${ }^{3341}$ or at worse is associated with minimal weight gain. ${ }^{16}$

No serious adverse events have been noted during the trials. In addition, patients rarely experienced hypoglycaemia unless medications were used in combination with sulfonylureas. Urea and electrolytes should be checked and monitored before and when starting treatment as the drug is mainly excreted by the kidney, with $80 \%$ excreted unchanged in the urine. ${ }^{47}$

Sitagliptin is currently licensed by the European Union (EU) and US Food and Drug Administration (FDA) in combination with metformin, sulfonylureas or TZDs. It is also approved for use in triple combination therapy with a sulfonylurea and metformin. The FDA has also approved its use as a monotherapy. Although vildagliptin was approved by the $\mathrm{EU}$ in October 2007 it still remains unapproved by the FDA which has requested further safety data in specific patient groups such as those with renal impairment. Vildagliptin is currently licensed for use as dual therapy in combination with metformin, sulfonylureas (in those for whom metformin is inappropriate) and TZDs.

Vildagliptin is not recommended for use in those with hepatic impairment including patients with pre-treatment values of alanine aminotransferase (ALT) or aspartate aminotransferase (AST) $>3$ times the upper limit of normal. It is recommended that liver function tests (LFTs) are performed before initiating treatment to obtain baseline values and then monitored at 3 monthly intervals for the first year of treatment. Treatment should be stopped if ALT and AST values rise above 3 times the upper limit of normal; once stopped, and the LFTs have returned to normal, treatment should not be re-initiated.

There is still some debate about where DPP-IV inhibitors fit into the management of T2DM. There may be a place in combination with metformin and TZDs; however, long term safety regarding cardiovascular outcomes and durability of the effect on glucose control still needs to be assessed.

\section{Rimonabant}

Rimonabant is the first agent of the class of drugs that act on the novel endocannabinoid system (ECS). The ECS is a novel physiological neuroendocrine system that plays a key role in appetite and energy metabolism, both in the brain and adipose tissue. ${ }^{48-50}$ Animal studies have shown that blocking the ECS leads to weight loss and improved insulin sensitivity. Due to this effect agents that block receptors (CB1 and CB2) in this system have been developed for the management of human obesity.

By blocking CB1 receptors, rimonabant has been shown to reduce weight by suppressing appetite and by modifying glucose and fat metabolism. ${ }^{50-52}$ It is usually given as $20 \mathrm{mg}$ once a day before breakfast. In the brain, rimonabant reduces hunger and therefore addresses weight loss, and in the adipose tissue the drug increases concentrations of adiponectin. This helps improve insulin sensitivity as reduced levels of adiponectin have been associated with increased insulin resistance. Due to this close link with various adipocytokines, agents within this group are hypothesised to be playing a role in atherogenesis and the pathophysiology of T2DM..$^{53}$

Rimonabant has undergone phase 3 trials and is licensed for use in patients who have a BMI $>30 \mathrm{~kg} / \mathrm{m}^{2}$ or BMI $>27 \mathrm{~kg} / \mathrm{m}^{2}$ with an additional risk factor such as dyslipidaemia or diabetes mellitus. Only four eligible randomised controlled trials (RCTs) and one meta-analysis were found through the search strategy. The therapeutic potential of rimonabant has been extensively investigated in the four so-called RIO studies: three in subjects without diabetes and one in subjects with diabetes. RIO-Europe and RIO-North America included patients who were obese or overweight with dyslipidaemia or hypertension. These studies showed a significant weight loss with rimonabant compared with placebo at 12 months. ${ }^{54} 55$ The RIO-Lipids study included overweight or obese patients with untreated dyslipidaemia and showed a significant weight reduction compared with placebo. ${ }^{56}$

The RIO-Diabetes study is the only published study using rimonabant in overweight or obese subjects with T2DM. ${ }^{57}$ In 


\section{Key references}

- Turner RC, Cull CA, Frighi V, et al. Glycemic control with diet, sulfonylurea, metformin, or insulin in patients with type 2 diabetes mellitus: progressive requirement for multiple therapies (UKPDS 49). UK Prospective Diabetes Study (UKPDS) Group. JAMA 1999;281:2005-12.

- Creutzfeldt W. The entero-insular axis in type 2 diabetes incretins as therapeutic agents. Exp Clin Endocrinol Diabetes 2001;109(S2):288-303.

- Amori RE, Lau J, Pittas AG. Efficacy and safety of incretin therapy in type 2 diabetes: systematic review and metaanalysis. JAMA 2007;298:194-206.

- Elrishi MA, Khunti K, Jarvis J, et al. The dipeptidyl-peptidase4 (DPP-4) inhibitors: a new class of oral therapy for patients with type 2 diabetes mellitus. Practical Diabetes International 2007;24:474-82.

- Christensen R, Kristensen PK, Bartels EM, et al. Efficacy and safety of the weight-loss drug rimonobant: a meta-analysis of randomized trials. Lancet 2007;370:1706-13.

this multicentre, randomised double blind placebo controlled trial, 1047 obese or overweight subjects with T2DM on sulfonylurea or metformin monotherapy were randomised to receive placebo (348), rimonabant $5 \mathrm{mg} /$ day (358), or rimonabant $20 \mathrm{mg} /$ day (339). Mean (SD) weight loss ( $\mathrm{kg}$ ) at the end of 1 year was 1.4 (3.6) vs 2.3 (4.2) vs 5.3 (5.2) for placebo, $5 \mathrm{mg}$ rimonabant and $20 \mathrm{mg}$ rimonabant, respectively. The proportion of patients achieving $>5 \%$ and $>10 \%$ weight loss was significantly greater in the rimonabant group $(49.4 \%$ vs $14.5 \%$, $\mathrm{p}<0.001$, and $16.4 \%$ vs $2 \%, \mathrm{p}<0.001$, for $>5 \%$ and $>10 \%$ weight loss, respectively). Mean (SD) HbA1c was reduced by 0.1 $(1.0) \%$ vs $0.1(1.0) \%$ vs $0.6(0.8) \%$ for the arms, respectively $(p<0.0001$ vs placebo). There was a similar reduction in mean (SD) HbA1c with $20 \mathrm{mg}$ rimonabant in subjects taking metformin $(-0.6(0.8) \%)$ and sulfonylureas $(-0.5(0.8) \%)$. More subjects receiving rimonabant $20 \mathrm{mg}$ required reduction of their oral hypoglycaemic agents. It is interesting to note that reduction in HbA1c (over 50\%) was independent of weight loss, suggesting direct peripheral actions of the drug on insulin resistance and adipocytes.

In the RIO-Diabetes study, the most common side effects (occurring in $>5 \%$ of subjects) were nausea, vomiting, diarrhoea, dizziness and anxiety. These were transient, self limiting and disappeared on persevering with the medication. Rates of adverse events and serious adverse events were higher in the rimonabant $20 \mathrm{mg}$ ( $8 \%$ and $15 \%$, respectively) compared with placebo (4\% and 5\%, respectively). Depressed mood disorders $(3 \%)$, anxiety $(0.6 \%)$ and nausea $(1.5 \%)$ were the most common side effects leading to discontinuation in the rimonabant $20 \mathrm{mg}$ arm. Due to the side effects the summary of product characteristics was altered to include concomitant antidepressants as a contraindication. The recently published meta-analysis (four RCTs, involving 4105 subjects) concluded the risks of discontinuation due to depressive mood disorders to be 2.5 times for rimonabant compared to placebo (odds ratio $2.5, \mathrm{p}=0.01$, numbers needed to harm $49(19-316)) .{ }^{58}$ The odds ratio for the incidence of suicide examined by the FDA from obesity studies for $20 \mathrm{mg}$ rimonabant versus placebo was 1.8 (0.8-3.8). Two deaths from suicide have been reported in the FDA database: one in RIO-North America in a patient taking

\section{Key learning points}

- Newer pharmacological agents for type 2 diabetes mean that treatment options are becoming more diverse.

- Newer agents are targeting some of the problem areas of the conventional agents such as weight gain and hypoglycaemia.

- Clinicians need to stay up to date with newer agents to ensure high quality diabetes care is available to patients.

\section{Current research questions}

- What is the durability of glucose control with new agents such as dipeptidyl peptidase (DPP-IV) inhibitors?

- What effect does the combination of glucagon-like polypeptide 1 (GLP-1) and insulin have in the obese?

- What is the cost effectiveness of GLP-1 and DPP-IV inhibitors if weight gain and hypoglycaemia are considered?

- What are the long term cardiovascular benefits of DPP-IV inhibitors, rimonabant and GLP-1 agonists.

rimonabant $5 \mathrm{mg}$, and one in a study in progress in a patient taking rimonabant $20 \mathrm{mg} .{ }^{59}$

In summary, rimonabant is efficacious in reducing weight, $\mathrm{HbA1c}$ and favourably altering the lipid profile in people with T2DM compared with placebo. However, the risks of depressive mood disorders need to be taken into consideration and at the moment it appears that judicious patient selection may improve benefit/risk ratio. Further long term studies are required examining cardiovascular end points.

In clinical practice, rimonabant is considered as an adjunct to lifestyle modifications in obese/overweight patients with T2DM, who do not achieve target $\mathrm{HbA1c}$ with existing treatment.

\section{CONCLUSION}

Pharmacological options for the treatment of T2DM have never been so diverse with the recent licensing of newer agents (table 3). Previously available treatments for T2DM have improved glycaemic control but have been accompanied by weight gain and increased risk of hypoglycaemia. T2DM is a progressive disease and more conventional agents do not address the decline of $\beta$ cell function.

Newer agents thus add to the choice of treatment options already available for T2DM and are welcome, especially in light of the recent safety concerns with some of the more modern agents. ${ }^{12}$ Newer agents such as exenatide, DPP-IV inhibitors and rimonabant have captured our attention as they address important issues in the management of T2DM, such as weight gain and hypoglycaemia.

The new agents covered in this review either show reductions in weight or are weight neutral and have a positive effect on concentrations of HbA1c when compared to placebo. Due to numerous emerging therapies in the treatment of T2DM, it is essential that clinicians update themselves regularly to ensure that their patients with T2DM are being treated appropriately. The agents reviewed in this paper are welcome novel treatments and provide us with new options for the management of T2DM; however, long term safety needs to be established, particularly in the light of recent data regarding TZDs. 
Competing interests: BTS is a named candidate on an investigator initiated study funded by Sanofi-Aventis and has accepted grants to attend conferences from GSK. MJD has received funds for research, honoraria for speaking at meetings and has served on Advisory Boards for Lily, Sanofi Aventis, MSD and Novo Nordisk. KK has received funds for research, honoraria for speaking at meetings and served on advisory boards for Astra Zeneca, GSK, Lily, Novartis, Pfizer, Servier, Sanofi Aventis, MSD and Novo Nordisk. JJ has no competing interests.

\section{REFERENCES}

1. Diabetes UK. Diabetes Prevalence 2007. http://www.diabetes.org.uk/en/Professionals/ Information resources/Reports/Diabetes-prevalence-2007/ (Accessed 2 May 2008)

2. Diabetes UK. Diabetes: State of the Nations 2005; Progress made in delivering the national diabetes frameworks. 9435/1205/a. 2005

3. Kannel WB, McGee DL. Diabetes and glucose tolerance as risk factors for cardiovascular disease: the Framingham study. Diabetes Care 1979;2:120-6.

4. UKPDS Group. UK Prospective Diabetes Study 6. Complications in newly diagnosed type 2 diabetic patients and their association with different clinical and biochemical risk factors. Diabetes Research 1990;13:1-11.

5. International Diabetes Federation. Diabetes atlas. Brussels: International Diabetes Federation, 2006

6. Turner R, Cull C, Holman RR. United Kingdom Prospective Diabetes Study 17: a 9 year update of a randomized, controlled trial on the effect of improved metabolic control on complications in non-insulin-dependent diabetes mellitus. Ann Intern Med 1996:124(1 Pt 2):136-45.

7. Turner RC, Holman RR, Stratton IM, et al. Effect of intensive blood-glucose control with metformin on complications in overweight patients with type 2 diabetes (UKPDS 34). Lancet 1998:352:854-65

8. Turner RC, Cull CA, Frighi V, et al. Glycemic control with diet, sulfonylurea metformin, or insulin in patients with type 2 diabetes mellitus: progressive requirement for multiple therapies (UKPDS 49). UK Prospective Diabetes Study (UKPDS) Group. JAMA 1999;281:2005-12.

9. Wright A, Burden AC, Paisey RB, et al. Sulfonylurea inadequacy: efficacy of addition of insulin over 6 years in patients with type 2 diabetes in the U.K. Prospective Diabetes Study (UKPDS 57). Diabetes Care 2002;25:330-6.

10. Bagg W, Plank LD, Gamble G, et al. The effects of intensive glycaemic control on body composition in patients with type 2 diabetes. Diabetes Obes Metab 2001;3:410-16.

11. Makimattila S, Nikkila K, Yki-Jarvinen $H$. Causes of weight gain during insulin therapy with and without metformin in patients with type II diabetes mellitus. Diabetologia 1999;42:406-12.

12. Nissen SE, Wolski K. Effect of rosiglitazone on the risk of myocardial infarction and death from cardiovascular causes. N Engl J Med 2007:356:2457-71.

13. Dormandy JA Charbonnel B, Eckland DK, et al. Secondary prevention of macrovascular events in patients with type 2 diabetes in the PROactice Study (PROspective pioglitaAzone Clinical Trial In MacroVascular Events): a randomised controlled trial. Lancet 2005;366:1279-89.

14. Elrick H, Stimmler L, Hlad CJ, et al. Plasma insulin response to oral and intravenous glucose administration. J Clin Endocrinol Metab 1964 24:1076-82.

15. Creutzfeldt W. The entero-insular axis in type 2 diabetes - incretins as therapeutic agents. Exp Clin Endocrinol Diabetes 2001;109(S2):288-303.

16. Amori RE, Lau J, Pittas AG. Efficacy and safety of incretin therapy in type 2 diabetes: systematic review and meta-analysis. JAMA 2007;298:194-206.

17. Baggio LL, Drucker DJ. Therapeutic approaches to preserve islet mass in type 2 diabetes. Annu Rev Med 2006;57:265-81.

18. Buse JB, Klonoff DC, Nielsen LL, et al. Metabolic effects of two years of exenatide treatment on diabetes, obesity, and hepatic biomarkers in patients with type 2 diabetes: an interim analysis of data from the open-label, uncontrolled extension of three double-blind, placebo-controlled trials. Clin Ther 2007:29:139-53.

19. Barnett AH. Exenatide. Drugs Today (Barc) 2005;41:563-78

20. Buse JB, Henry RR, Han J, et al. Effects of exenatide (exendin-4) on glycemic control over 30 weeks in sulfonylurea-treated patients with type 2 diabetes. Diabetes Care 2004;27:2628-35

21. DeFronzo RA, Ratner RE, Han J, et al. Effects of exenatide (exendin-4) on glycemic control and weight over 30 weeks in metformin-treated patients with type 2 diabetes. Diabetes Care 2005;28:1092-100.

22. Kendall DM, Riddle MC, Rosenstock J, et al. Effects of exenatide (exendin-4) on glycemic control over 30 weeks in patients with type 2 diabetes treated with metformin and a sulfonylurea. Diabetes Care 2005;28:1083-91.

23. Zinman B, Hoogwerf BJ, Duran GS, et al. The effect of adding exenatide to a thiazolidinedione in suboptimally controlled type 2 diabetes: a randomized trial. [erratum appears in Ann Intern Med 2007;146:896] [summary for patients in Ann Intern Med 2007:146:118]. Ann Intern Med 2007:146:477-85.

24. Heine RJ, Van Gaal LF, Johns D, et al. Exenatide versus insulin glargine in patients with suboptimally controlled type 2 diabetes: a randomized trial. Ann Intern Med 2005:143:559-69.

25. Nauck MA, Duran S, Kim D, et al. A comparison of twice-daily exenatide and biphasic insulin aspart in patients with type 2 diabetes who were suboptimally controlled with sulfonylurea and metformin: a non-inferiority study. Diabetologia 2007:50:259-67.

26. Barnett AH BJJD. Tolerability and efficacy of exenatide and titrated insulin glargine in adult patients with type 2 diabetes previously uncontrolled with metformin or a sulphonylurea: a multinational, randomized, open-label, two-period, crossover noninferiority trial. Clin Ther 2007:29:2333-48.
27. Anon. Information for Healthcare Professionals Exenatide (marketed as Byetta). 2007.

28. Madsbad S, Schmitz 0, Ranstam J, et al. Improved glycemic control with no weight increase in patients with type 2 diabetes after once-daily treatment with the longacting glucagon-like peptide 1 analog liraglutide (NN2211): a 12-week, double-blind randomized, controlled trial. Diabetes Care 2004;27:1335-42.

29. Scottish Medicines Consortium. Exenatide, 5 or 10 micrograms, solution for injection, prefilled pen No.(376/07). http://www.scottishmedicines.org.uk/smc/5376. html. (Accessed 1 June 2008)

30. National Institute for Health and Clinical Excellence. Type 2 diabetes: the management of type 2 diabetes, update of NICE clinical guidelines E, F, G and H. NICE Clinical Guideline 66. London: NICE, May 2008.

31. Elrishi MA, Khunti K, Jarvis J, et al. The dipeptidyl-peptidase-4 (DPP-4) inhibitors: a new class of oral therapy for patients with type 2 diabetes mellitus. Practical Diabetes International 2007;24:474-82.

32. Raz I, Hanefeld M, Xu L, et al. Efficacy and safety of the dipeptidyl peptidase-4 inhibitor sitagliptin as monotherapy in patients with type 2 diabetes mellitus. Diabetologia 2007:49:2564-71.

33. Aschner P, Kipnes MS, Lunceford JK, et al. Effect of the dipeptidyl peptidase-4 inhibitor sitagliptin as monotherapy on glycemic control in patients with type 2 diabetes. Diabetes Care 2006:29:2632-7.

34. Pi-Sunyer FX, Schweizer A, Mills D, et al. Efficacy and tolerability of vildagliptin monotherapy in drug-naive patients with type 2 diabetes. Diabetes Research Clinical Practice 2007:76:132-8.

35. Schweizer A, Couturier A, Foley JE, et al. Comparison between vildagliptin and metformin to sustain reductions in $\mathrm{HbA}(1 \mathrm{c})$ over 1 year in drug-naive patients with type 2 diabetes. Diabet Med 2007;24:955-61.

36. Goldstein BJ, Feinglos MN, Lunceford JK, et al. Effect of initial combination therapy with sitagliptin, a dipeptidyl peptidase-4 inhibitor, and metformin on glycemic control in patients with type 2 diabetes. Diabetes Care 2007;30:1979-87.

37. Ahren B, Gomis R, Standl E, et al. Twelve- and 52-week efficacy of the dipeptidy peptidase IV inhibitor LAF237 in metformin-treated patients with type 2 diabetes. Diabetes Care 2004:30:217-23.

38. Bosi E, Camisasca RP, Collober C, et al. Effects of vildagliptin on glucose control over 24 weeks in patients with type 2 diabetes inadequately controlled with metformin Diabetes Care 2007:30:890-5.

39. Charbonnel B, Karasik A, Liu J, et al. Efficacy and safety of the dipeptidyl peptidase4 inhibitor sitagliptin added to ongoing metformin therapy in patients with type 2 diabetes inadequately controlled with metformin alone. Diabetes Care 2006;29:2638-43

40. Garber A, Camisaca RP, Ehrsam E, et al. Vildagliptin added to metformin improves glycaemic control and may mitigate metformin-induced GI side effects in patients with type 2 diabetes (T2DM). Diabetes 2006;55(Suppl 1):A29:121-0R.

41. Garber AJ, Camisaca RP, Jauffret $S$, et al. Efficacy and tolerability of vidigliptin added to a sulfonylurea (SU) in patients with type 2 diabetes (T2DM). Diabetes 2007:56(Suppl 1):0501-P.

42. Hermansen $\mathbf{K}$, Kipnes M, Luo E, et al. Efficacy and safety of the dipeptidy peptidase-4 inhibitor, sitagliptin, in patients with type 2 diabetes mellitus inadequately controlled on glimepiride alone or on glimepiride and metformin. Diabetes Obes Metab 2007;9:733-45.

43. Nauck MA, Meininger G, Sheng D, et al. Efficacy and safety of the dipeptidy peptidase- 4 inhibitor, sitagliptin, compared with the sulfonylurea, glipizide, in patients with type 2 diabetes inadequately controlled on metformin alone: a randomized, double-blind, non-inferiority trial. Diabetes Obes Metab 2007:9:194-205.

44. Rosenstock J, Baron MA, Dejager S, et al. Comparison of vildagliptin and rosiglitazone monotherapy in patients with type 2 diabetes: a 24-week, double-blind, randomized trial. [erratum appears in Diabetes Care 2007;30:1330]. Diabetes Care 2007:30:217-23.

45. Rosenstock J, Brazg R, Andryuk PJ, et al. Efficacy and safety of the dipeptidyl peptidase-4 inhibitor sitagliptin added to ongoing pioglitazone therapy in patients with type 2 diabetes: a 24-week, multicenter, randomized, double-blind, placebocontrolled, parallel-group study. Clin Ther 2006;28:1556-68.

46. Fonseca V, Schweizer A, Albrecht D, et al. Addition of vildagliptin to insulin improves glycaemic control in type 2 diabetes. Diabetologia 2007:50:1148-55.

47. Herman GA, Stevens C, Van Dyck K, et al. Pharmacokinetics and pharmacodynamics of single doses of sitagliptin, an inhibitor of dipeptidyl peptidase-IV, in healthy subjects. Clin Pharmacol Ther 2005;78:675-88

48. Cota D, Marsicano G, Tschop M, et al. The endogenous cannabinoid system affects energy balance via central orexigenic drive and peripheral lipo-genesis. J Clin Invest 2003;112:423-31.

49. Di Marzo V, Matias I, et al. Endocannabinoid control of food intake and energy balance. Nat Neurosci 2005;8:585-9.

50. Wynne K, Stanley S, McGowan B, et al. Appetite control. J Endocrinol 2005:184:291-318

51. Jbilo 0, Ravinet-Trillou C, Arnone M, et al. The CB1 receptor antagonist rimonabant reverses the diet-induced obesity phenotype through the regulation of lipolysis and energy balance. FASEB J 2005;19:1567-9.

52. Rinaldi-Carmona M, Barth F, Heaulme M, et al. SR141716A, a potent and selective antagonist of the brain cannabinoid receptor. FEBS Lett 1994;350:240-4.

53. Finer N, Pagotto U. The endocannabinoid system: a new therapeutic target for cardiovascular risk factor management. Br J Diabetes Vasc Dis 2005:5:121-4. 
54. Pi-Sunyer FX, Aronne LJ, Heshmati HM, et al. Effect of rimonabant, a cannabinoid-1 receptor blocker, on weight and cardiometabolic risk factors in overweight or obese patients: RIO-North America: a randomized controlled trial. JAMA 2006;295:761-75.

55. Van Gaal LF, Rissanen AM, Scheen AJ, et al. Effects of the cannabinoid-1 receptor blocker rimonabant on weight reduction and cardiovascular risk factors in overweight patients: 1-year experience from the RI0-Europe study. Lancet 2005;365:1389-97.

56. Despres J-P, Golay A, Sjostrom L. Effects of rimonabant on metabolic risk factors in overweight patients with dyslipidemia. N Engl J Med 2005;353:2121-34.
57. Scheen AJ, Van Gaal LG, Despres JP, et al. Rimonabant improves cardiometabolic risk profile in obese or overweight subjects: overview of RIO studies. Rev Med Suisse 2006;2:1916-23.

58. Christensen R, Kristensen PK, Bartels EM, et al. Efficacy and safety of the weight-loss drug rimonobant: a meta-analysis of randomized trials. Lancet 2007;370:1706-13

59. US Food and Drug Administration Advisory Committee. FDA briefing document Zimulti (rimonabant) tablets, 20 mg. Rockville: FDA, 2007.

Quality \& Safety in Health Care

Quality \& Safety in Health Care is a leading international peer-review journal in the growing area of quality and safety improvement. It provides essential information for those wanting to reduce harm and improve patient safety and the quality of care. The journal reports and reflects research, improvement initiatives and viewpoints and other discursive papers relevant to these crucial aims with contributions from researchers, clinical professionals and managers and experts in organisational development and behaviour.

qshc.bmj.com 